\title{
REVIEW
}

Open Access

\section{Scoping review of biological treatment of deficiency of interleukin-36 receptor antagonist (DITRA) in children and adolescents}

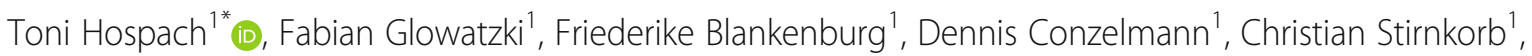
Chris Sandra Müllerschön², Peter von den Driesch², Lisa Maria Köhler ${ }^{3}$, Meino Rohlfs ${ }^{3}$, Christoph Klein ${ }^{3}$ and Fabian Hauck ${ }^{3}$

\begin{abstract}
Background: Deficiency of interleukin-36 receptor antagonist (DITRA) is a life threatening monogenic autoinflammatory disease caused by loss of function mutations in the IL36RN gene. Affected patients develop recurrent episodes of generalized pustular psoriasis (GPP) with systemic inflammation and fever. We here review and analyze the literature on pediatric DITRA patients who have been treated by biologicals targeting inflammatory cytokines.

Method: A database research was performed to identify all relevant articles on pediatric DITRA patients treated with biologicals. According to defined response criteria therapeutic efficacy was analyzed.

Results: Our literature research revealed 12 pediatric patients with DITRA who have received treatment with biologicals and we add a further not yet reported patient. Out of these 13 patients 10 were homozygous including 6 with the p.Leu27Pro, 3 with the p.Arg10 Argfs* and 1 with the p.Thr123Met mutation. 3 patients were compound heterozygous. In total 28 flares were treated with biological agents- targeting IL-1, IL-17, IL-12/23 and TNF-a. Complete response was achieved in 16 flares (57\%), a partial reponse was seen in 2 flares (7\%), and no response was observed in 10 flares (36\%). Response rates were heterogeneous among the different agents. While complete/partial/no response with inhibition of TNF-alpha could be achieved in 7 (58\%)/1 (8\%)/4 (33\%), the inhibition of IL-17 and of IL-12/23 led in each 4 flares to a 100\% complete response. IL-1 inhibition led to complete/partial response in each $1(13 \%)$ and was not effective in 6 (76\%) flares. Of note, the novel patient was successfully treated with weekly dosed adalimumab.
\end{abstract}

Conclusions: DITRA is a rare disease that has to be considered in GPP with systemic inflammation and fever. It can be effectively treated with specific biological inhibition of TNF-alpha, IL-12/23 and IL-17, while anti-IL-1 treatment seems less effective. Weekly dosed adalimumab appears to be a treatment option for pediatric patients. Further reports and studies of biological treated pediatric DITRA patients are warranted for evaluation of optimal treatment.

Keywords: Generalized pustular psoriasis (GPP), IL36RN, Autoinflammation, DITRA, Deficiency of interleukin-36 receptor antagonist, Monogenic disease, Biologicals, Adalimumab

\footnotetext{
* Correspondence: a.hospach@klinikum-stuttgart.de

'Department of Pediatric Rheumatology, Klinikum Stuttgart, Olgahospital

Stuttgart, Stuttgart, Germany

Full list of author information is available at the end of the article
}

C The Author(s). 2019 Open Access This article is distributed under the terms of the Creative Commons Attribution 4.0 International License (http://creativecommons.org/licenses/by/4.0/), which permits unrestricted use, distribution, and reproduction in any medium, provided you give appropriate credit to the original author(s) and the source, provide a link to the Creative Commons license, and indicate if changes were made. The Creative Commons Public Domain Dedication waiver (http://creativecommons.org/publicdomain/zero/1.0/) applies to the data made available in this article, unless otherwise stated. 


\section{Background}

Deficiency of interleukin-36 receptor antagonist (DITRA) is a life-threatening autoinflammatory disease caused by autosomal-recessive mutations in the interleukin-36 receptor (L36RN gene, OMIM 614204). Interleukin-36 receptor antagonist (IL-36RA) is an IL-1 family member that antagonizes proinflammatory signals of the IL-36 family members (IL-36 $\alpha$, IL36 $\beta$ and IL36 $\gamma$ ) [9, 12, 36]. The major pathogenic role leading to skin and systemic inflammation is the impairment of the processing and regulatory function of IL-36RA [1]. Affected patients suffer from recurrent episodes of generalized pustular psoriasis (GPP) with systemic inflammation and fever [22]. Among the patients with GPP it was shown that mutations in the IL36RN gene, leading to DITRA, account for 21 to $82 \%$ of the disease [2, 16, 18, 23, 33]. Clinically, DITRA is different from GPP. DITRA patients have a younger age at onset and a higher risk of systemic inflammation [2, 16, 39]. DITRA is a rare disease, most often presenting in early childhood or adolescence. So far, no more than 200 patients have been reported - most of them from Asia [16, 21, 34, 38-40].

Treatment guidelines for adult and pediatric GPP do exist but are not available for DITRA [30]. Acitretin (ACI) has efficacy in inducing temporary remission. However, relapses are common and therapy for patients with refractory courses remains a clinical challenge [20,39]. A recently published review on adult GPP showed the efficacy of targeted immunotherapy, e.g. that of TNF- $\alpha$, IL-17, IL-12/23 and IL-1 blocking agents [2]. Therefore, the aim of our literature research was to summarize the data on pediatric DITRA patients treated with biologicals.

Furthermore we add our experience of one novel patient who was successfully treated with weekly dosed adalimumab, a treatment that was -to the best of our knowledge- not reported before in pediatric DITRA.

\section{Method}

For scoping research we entered the terms "Deficiency of interleukin-36 receptor antagonist", "Deficiency of interleu kin-36 antagonist", "IL36RN mutation" and "DITRA" into the NCBI pubmed, EMBO, Scielo, LIVIVO, and sciencedirect databases to identify all relevant articles from its inception to October 2018. The language was limited to English and German. Articles with disease age at onset over 18 years and those without biological treatment were excluded.

As there are no standardized response criteria for DITRA available we defined response as follows:

1. Complete response (CR) was defined as the absence of disease associated skin manifestations for at least one month. In this category patients were grouped reported to be in "total remission", "complete remission", "good response", "free of skin eruptions", "completely cleared skin".

2. Partial response (PR) was defined as improvement -but still presence- of disease associated skin manifestations. In this category patients were grouped reported to be in "partial remission or partial response", "positive effect, but not in total remission", "no significant response".

3. No response (NR) was defined as lack of improvement or deterioration of disease associated skin manifestation. In this category patients were grouped reported to have "no response", "uncontrolled disease", "no improvement" or "failure to treatment".

4. A flare was defined as disease associated skin manifestation necessitating treatment change. Mild relapses were not defined as flare.

5. A mild relapse was defined as exacerbation that did either not require treatment, could be controlled with local treatment, with acitretin or only with dose modification of the already used biological.

We identified 105 articles with the above mentioned search terms and excluded 90 that did not meet the inclusion criteria with age at onset below 18 years and/or biological treatment. Four articles were excluded for insufficient clinical and response data (e.g. duration of treatment). Of the remaining 11 articles all but one were single case reports [3] Fig. 1.

Informed consent was obtained of both parents in written and of the pediatric patient in oral form for publishing the case report and the pictures.

\section{Case report}

We report on a 5-year-old boy with recurrent severe acute exacerbations of generalized pustular psoriasis with fever. Starting at the age of 7 months (Fig. 2) he suffered from fever and psoriatic lesions. Diagnosis was "early onset psoriasis with probable infection", although a causing infectious agent could not be recovered. Under initial treatment with antibiotics and with weekly methotrexate (MTX, $10 \mathrm{mg} / \mathrm{sqm}$ ) and varying doses of prednisolone he responded completely over the course of several weeks. At the age of three years MTX could be stoppend. At the age of 4 years (Fig. 3) he again presented with fever and generalized psoriasis, being diagnosed as "generalized psoriasis". With high doses of prednisolone ( $2 \mathrm{mg} / \mathrm{kg}$ ), MTX (10 mg/ sqm) and topical treatment he showed a partial response with recurrent lesions on the trunk. While prednisolone was tapered during the following weeks MTX was continued. The latest admission at the age of 5 years was necessary for severe pustular and psoriatic skin lesions covering $60 \%$ of his skin (Fig. 4). He had fever and CRP was elevated up to $11,8 \mathrm{mg} / \mathrm{dl}$. Abdominal ultrasound revealed hepatosplenomegaly, thickened bileducts and ascites. 


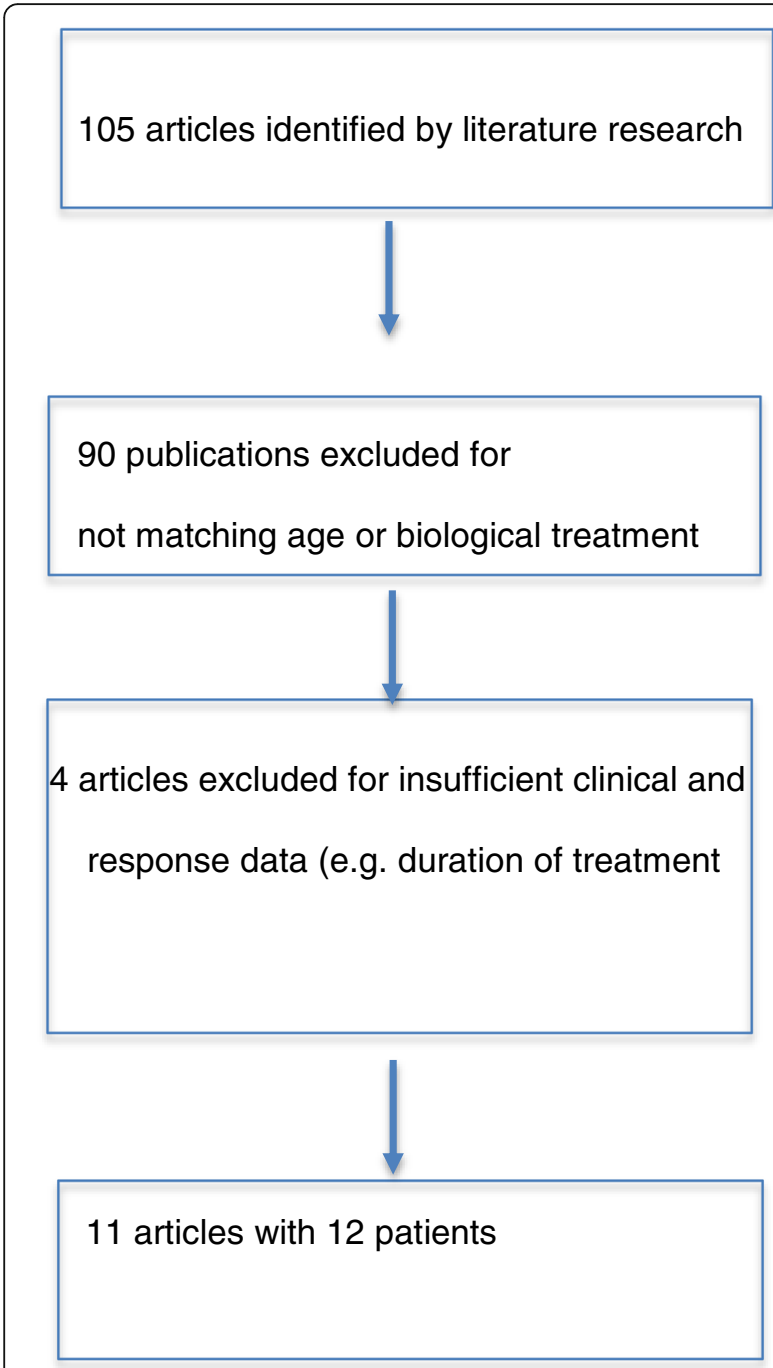

Fig. 1 Flow chart of literature research

Echocardiography revealed pericardial and pleural effusion. Lipase and $\mathrm{y}$-GT were elevated to $2480 \mathrm{U} / \mathrm{l}$ and 213 $\mathrm{U} / \mathrm{l}$, respectively; ALT and AST were in normal ranges. Diagnosis then was "generalized pustular psoriasis". We started methylprednisolone pulses $(20 \mathrm{mg} / \mathrm{kg})$ for 3 days and continued with prednisolone $2 \mathrm{mg} / \mathrm{kg} / \mathrm{d}$-additive to methotrexate $10 \mathrm{mg} / \mathrm{sqm}$ with minor efficacy related to the skin. After introduction of adalimumab $20 \mathrm{mg}$ (body weight $16 \mathrm{~kg}$ ) every week the skin cleared completely within 2 weeks, with normal temperatures and CRP values as well as yGT and lipase. Echocardiography and ultrasound of the abdomen normalized. After 12 months the boy is in complete remission with adalimumab in weekly intervals and MTX $10 \mathrm{mg} / \mathrm{sqm}$ (Fig. 5).

To establish a definitive diagnosis, exom sequencing was performed on the patient and his parents. Initially, we assumed consanguinity and filtered accordingly for a homozygous STXBP2 variant (c.568C > T; p.Arg190Cys).

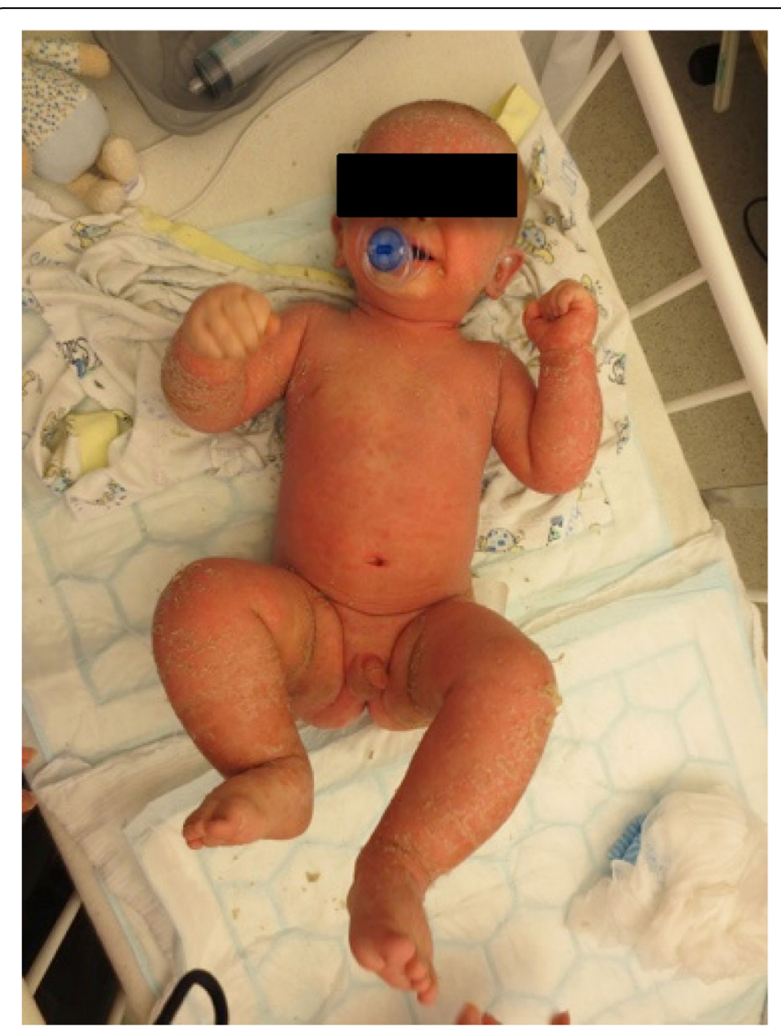

Fig. 2 Generalized psoriatic lesions at the age of 7 month

Pathogenic autosomal recessive STXBP2 variants can lead to familial hemophagocytic lymphohistiocytosis type 5 (FHL5) and the systemic inflammatory response observed in the patient could have indeed been an atypical FHL5 manifestation [27]. However, functional testing of NK cell degranulation was normal and the variant was therefore considered benign [4]. Next, the exome data were re-analysed assuming non-consanguinity and two variants in the IL36RN gene were identified. Sanger sequencing of both parents and the patient confirmed compound heterozygous IL36RN variants (c.227C > T; p.Pro76Leu and c.338C > T; pSer113Leu). In light of the clinical phenotype, the genetic data is consistent is in line with establishing the diagnosis DITRA.

\section{Results of the literature research}

Our literature research revealed 13 pediatric DITRA patients - including the one reported here - treated with biologicals (Table 1). All but one were pretreated with multiple nonbiological agents. Male to female ratio was 10:3. Median age at onset was 7 month (range 0.5-192 months), whereas median age at genetic diagnosis was 55 months (range 2-204 months) summing up to a diagnostic delay of 47 months. 10 patients were homozygous for a mutation in $I L 36 R N$, including 6 with the p.Leu27Pro mutation representing the most common mutation, 3 with the p.Arg10 Argfs* splice mutation and one with 


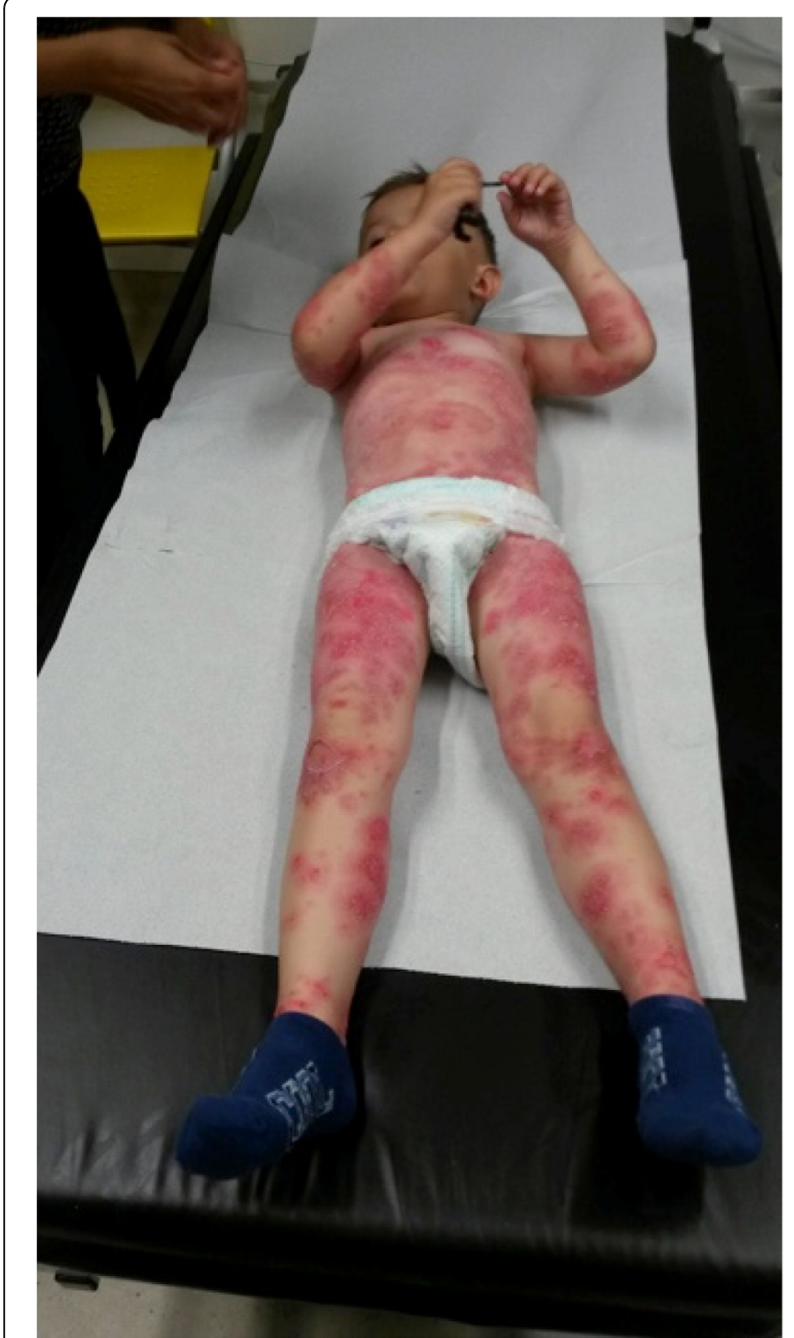

Fig. 3 Generalized psoriasis at the age of 4 years

the p.Thr123Met mutation. Three patients were compound heterozygous (Table 1) for mutations in IL36RN. In total, 28 flares in 13 patients were treated with biological agents. Median treatment duration was 5.5 months (range 0,1-36 months). Concomitant treatment with DMARDs, ACI, IVIG or PRED was given in 6 flares in general, and in 4 flares with CR (low dose MTX and PRED, ACI and IVIG). Complete response was achieved in $57 \%$ of the flares. Partial response was seen in $7 \%$, while no response was reported in $36 \%$ of the flares. Response rates were heterogeneous among the different agents. While complete/partial/no response with inhibition of TNF-alpha could be achieved in $58 \% / 8 \% / 33 \%$ of the flares, the inhibition of IL-17 and of IL-12/23 led to a $100 \%$ complete response. IL-1 inhibition led to complete/partial response in each $13 \%$ and was not effective in $76 \%$ of the flares. Follow-up intervals after cessation of treatment were only reported in two patients (Table 3, for details see Table 2).

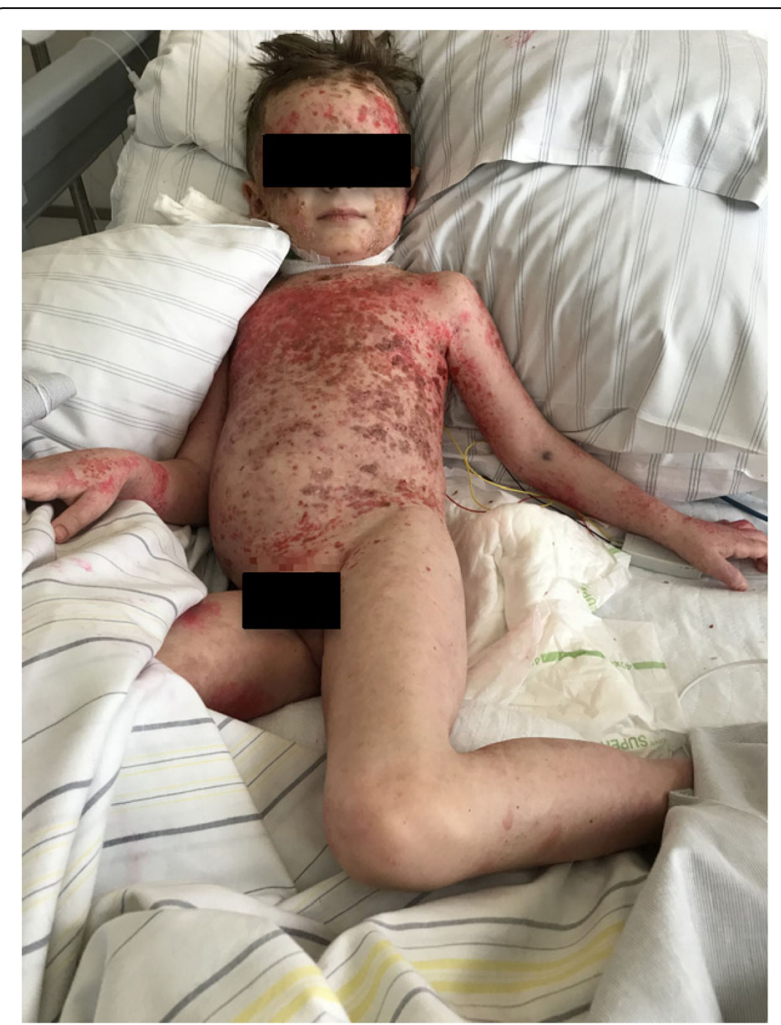

Fig. 4 Psoriatic and pustular lesions before current treatment with adalimumab at age of 5 years

\section{Discussion}

In pediatric patients with systemic inflammation and GPP monogenic diseases like deficiency of interleukin 1 receptor antagonist (DIRA), DITRA and caspase activation and recruitment domain (CARD) 14-mediated psoriasis (CAMPS) have to be considered [13, 25]. Our study highlights a marked delay of 47 months between age at onset and genetically confirmed diagnosis. Thus, clinical awareness should be raised in order to rapidly initiate genetic testing and effective treatment. In these

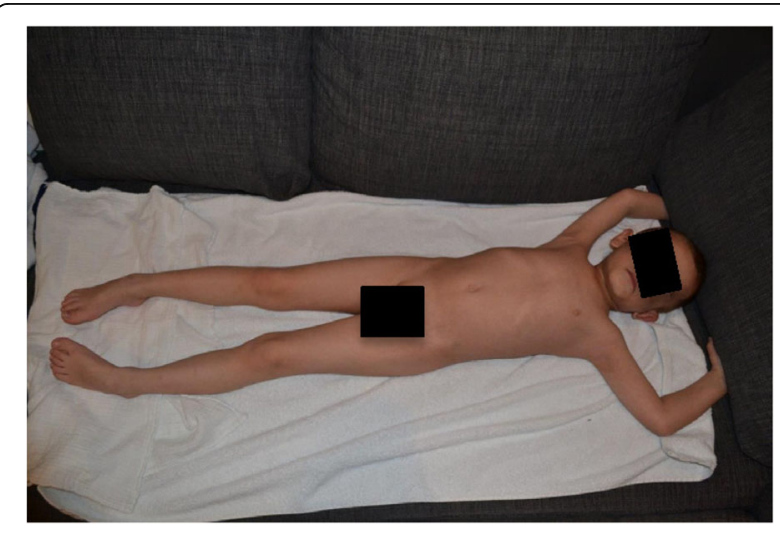

Fig. 5 Complete resolution after treatment with adalimumab in weekly intervals 
Table 1 Patient characteristics of 13 pediatric DITRA patients treated with biological agents

\begin{tabular}{|c|c|c|c|c|c|c|}
\hline Case & $\begin{array}{l}\text { Age at onset/genetically confirmed } \\
\text { diagnosis in months }\end{array}$ & $\operatorname{sex}$ & $\begin{array}{l}\text { Mutation c }(p) \\
\text { nomenclature }\end{array}$ & Zygosity & $\begin{array}{l}\text { Previous treatment failures } \\
\text { with nonbiological agents }\end{array}$ & Author \\
\hline 1 & $72 / 96$ & M & $\begin{array}{l}\text { c. } 115+6 \mathrm{~T}>\mathrm{C} \\
(\text { p.Arg10Argfs } *)\end{array}$ & ho & CSA, MPP, ACl & {$[28]$} \\
\hline 2 & "infancy"/"adolescence" & M & $\begin{array}{l}\text { c. } 115+6 \mathrm{~T}>\mathrm{C} \\
(\text { p.Arg10Argfs } *)\end{array}$ & ho & ACl, CSA, PUVA, PRED, MTX, APRE & [8] \\
\hline 3 & $1 / 72$ & M & $\begin{array}{l}\text { c. } 115+6 \mathrm{~T}>\mathrm{C} \\
(\text { p.Arg10Argfs*) }\end{array}$ & ho & $\mathrm{CS}, \mathrm{MTX}, \mathrm{ACl}, \mathrm{CSA}$ & {$[15]$} \\
\hline 4 & $0.5 / 6$ & M & $\begin{array}{l}\text { c.80T }>\text { C } \\
\text { (p.Leu27Pro) }\end{array}$ & ho & - & {$[31]$} \\
\hline 5 & $2 / 36$ & M & $\begin{array}{l}\text { c.80 T > C } \\
\text { (p.Leu27Pro) }\end{array}$ & ho & Topical CS, systemic RET & {$[5]$} \\
\hline 6 & $41 / 48$ & M & $\begin{array}{l}\text { c.80T }>\text { C } \\
\text { (p.Leu27Pro) }\end{array}$ & ho & CS, MTX & [19] \\
\hline 7 & $2 / 17$ & $\mathrm{~F}$ & $\begin{array}{l}\text { c.80 T > C } \\
\text { (p.Leu27Pro) }\end{array}$ & ho & $\mathrm{CSA}, \mathrm{ACl}$ & [10] \\
\hline 8 & $1 / 2$ & M & $\begin{array}{l}\text { c. } 80 \mathrm{~T}>\mathrm{C} \\
\text { (p.Leu27Pro) }\end{array}$ & ho & Topical CS, ACI & {$[6]$} \\
\hline 9 & $1 / 60$ & $\mathrm{~F}$ & $\begin{array}{l}\text { c. } 80 T>C \\
\text { (p.Leu27Pro) }\end{array}$ & ho & $\mathrm{CS}, \mathrm{ACl}, \mathrm{CSA}$ & {$[3]$} \\
\hline 10 & NA/"adolescence" & M & $\begin{array}{l}\text { c.368C > T } \\
\text { (p.Thr123Met) }\end{array}$ & ho & MTX, ACl & [24] \\
\hline 11 & 84/NA & $\mathrm{F}$ & $\begin{array}{l}\text { c.142C > T/c.338C > T } \\
\text { (pArg48Trp)/p.Ser113Leu) }\end{array}$ & comp het & PRED, ACI, ISO, MTX, CSA & {$[26]$} \\
\hline 12 & $7 / 60$ & M & $\begin{array}{l}\text { c.227C > T/c.338C > T } \\
(\text { p.Pro76Leu)/(pSer113Leu) }\end{array}$ & comp het & MTX, CS & Patient reported here \\
\hline 13 & $36 / 48$ & M & $\begin{array}{l}\text { c.227C > T/c.338C > T } \\
\text { (p.Pro76Leu/p.Ser113Leu) }\end{array}$ & comp het & CS, CSA, THAL, DAP & [3] \\
\hline
\end{tabular}

Abbr:ACl-acitretin, APRE-apremilast, CS-corticosteroids, CSA-ciclosporine, DAP-dapsone, ho-homozygosity, het-heterozygosity, comp het-compound heterzygosity, ISO-isotretinoin MPP-methylprednisolone, MTX-methotrexate, NA-not available, PRED-prednisolone, PUVA-psoralen plus UVA, RET-retionoids, THAL-thalidomide.

diagnostic procedures close collaboration with experts in clinical immunology, rheumatology, dermatology, and molecular genetics is advisable for correct interpretation of the plethora of polymorphisms and identification of pathological mutations. Our clinical case illustrates these challenges. A homozygous variant in the STXBP2 gene (c.568C > T; p.Arg190Cys), initially interpreted as possible cause for atypical FHL5, could eventually be excluded through repetitive interdisciplinary discussions, in-depth functional immune assays, and re-interpretation of exome sequencing data - testifying to the value of good interdisciplinary collaboration in the best interest of patients.

Whereas the pathogenicity of the IL36RN mutations in the patient remains to be formally proven, both compound heterozygous IL36RN mutations have been reported in DITRA patients before. The mutation c. $227 \mathrm{CY}>\mathrm{T}$; p.Pro 76Leu has been described as an amorphic variant, the mutation c.338C > T; pSer113Leu was considered to be hypomorphic [34]. This compound heterozygous mutation has also been reported in another patient [3]. To the best of our knowledge associations of FHL5 and IL36RN gene variants have not been reported so far.
Early treatment of GPP is essential to prevent bacterial superinfection and probably death that was estimated to occur in $4-7 \%[2,7,17]$. Treatment recommendations for GPP in children do exist from the American Board of National Psoriasis Foundation and include acitretin, cyclosporine A, methotrexate and etanercept as first line treatment and adalimumab, infliximab and ultraviolet $\mathrm{B}$ phototherapy as second line treatment [30]. As no guidelines exist for therapy of DITRA and a recent report on targeted immunotherapy in GPP exclusively addresses adults it is important to collect data on the efficacy of biological treatment for children. The rational for treatment with biological agents is given through significant overexpression of Il-17A, TNF- $\alpha$, IL-1, IL-36 in GPP and in psoriasis (see Fig. 6).

Our literature research showed that biologically treated DITRA flares resulted in $57 \%$ in complete response. This is comparable to the data on 101 adult cases with GPP -including four DITRA patients- where $61 \%$ showed complete response [2]. This is also true for the response rates to TNF-alpha blocking agents. Each $58 \%$ in pediatric and adult GPP patients showed a 
Table 2 Detailed overview of treatment with biological agents in 28 flares of 13 pediatric patients

\begin{tabular}{|c|c|c|c|c|c|c|c|c|}
\hline Target & Drug & Dose & $\begin{array}{l}\text { Pustule } \\
\text { cleareance (day) }\end{array}$ & $\begin{array}{l}\text { Clinical improvement } \\
\text { number of patients/total } \\
\text { number treated }\end{array}$ & $\begin{array}{l}\text { Clinical } \\
\text { response type }\end{array}$ & $\begin{array}{l}\text { Concomitant } \\
\text { systemic treatment }\end{array}$ & $\begin{array}{l}\text { Treatment } \\
\text { duration (months) }\end{array}$ & $\overline{\text { Reference }}$ \\
\hline \multirow[t]{12}{*}{ TNF-a } & \multirow[t]{5}{*}{ ETA } & NA & NA & $1 / 1$ & $P R$ & MTX & 4 & {$[19]$} \\
\hline & & $\begin{array}{l}0.4 \mathrm{mg} / \mathrm{kg} \text { twice per } \\
\text { wk }\end{array}$ & NA & $1 / 1$ & $C R^{*}$ & NA & 7 & {$[15]$} \\
\hline & & $12.5 \mathrm{mg} / \mathrm{wk}$ & 35 & $1 / 1$ & $C R$ & $\mathrm{ACl} 1 \mathrm{mg} / \mathrm{kg} / \mathrm{d}$ & 6 & {$[10]$} \\
\hline & & NA & NA & $0 / 1$ & $N R$ & $\mathrm{ACl}$ & 7 & {$[3]$} \\
\hline & & $0.8 \mathrm{mg} / \mathrm{kg} / \mathrm{wk}$ & NA & $0 / 1$ & $N R$ & - & 3 & {$[6]$} \\
\hline & \multirow[t]{4}{*}{ ADA } & 20 mg /every 2 wk & NA & $0 / 1$ & NR & NA & NA & [15] \\
\hline & & NA & NA & $1 / 1$ & $C R^{* *}$ & NA & 26 & {$[8]$} \\
\hline & & NA & NA & $0 / 1$ & $N R$ & NA & 1 & {$[3]$} \\
\hline & & 20 mg every wk & 7 & $1 / 1$ & $C R$ & - & 8 & $\begin{array}{l}\text { Patient } \\
\text { reported } \\
\text { here }\end{array}$ \\
\hline & \multirow[t]{3}{*}{$\mathrm{IFL}$} & $\begin{array}{l}100 \mathrm{mg} \text { in } 2 \mathrm{wk} \text {. } \\
\text { interval, in total } \\
2 \text { infusions }(3,3 \\
\mathrm{mg} / \mathrm{kg})\end{array}$ & 14 & $1 / 1$ & $C R^{* *}$ & - & $0,5^{* * *}$ & {$[28]$} \\
\hline & & 5 mg/kg & NA & $1 / 1$ & $C R^{* *}$ & NA & 9 & {$[8]$} \\
\hline & & NA & NA & $1 / 1$ & $C R$ & NA & 1 & {$[26]$} \\
\hline \multirow[t]{8}{*}{ IL-1 } & \multirow[t]{7}{*}{ ANA } & $4 \mathrm{mg} / \mathrm{kg} / \mathrm{d}$ & 7 & $1 / 1$ & $C R$ & - & 2 & [31] \\
\hline & & $5 \mathrm{mg} / \mathrm{kg} / \mathrm{d}$ & NA & $0 / 1$ & NR & NA & 3 & {$[5]$} \\
\hline & & $100 \mathrm{mg} / \mathrm{d}$ & NA & $0 / 1$ & NR & NA & 3 days & [8] \\
\hline & & $6 \mathrm{mg} / \mathrm{kg} / \mathrm{d}$ & NA & $0 / 1$ & NR & NA & NA & [19] \\
\hline & & $5 \mathrm{mg} / \mathrm{kg} / \mathrm{d}$ & NA & $0 / 1$ & $N R$ & NA & NA & [10] \\
\hline & & NA & NA & $0 / 2$ & NR & NA & $2 / 0,2$ & [3] \\
\hline & & $6 \mathrm{mg} / \mathrm{kg} / \mathrm{d}$ & Partial & $1 / 1$ & $P R$ & - & 36 & [6] \\
\hline & CAN & $\begin{array}{l}3 \mathrm{mg} / \mathrm{kg} / \mathrm{d} \\
\text { every } 8 \mathrm{wks}\end{array}$ & NA & $0 / 1$ & $N R$ & NA & NA & [5] \\
\hline \multirow{3}{*}{$\begin{array}{l}\mathrm{IL} 12 / \\
23\end{array}$} & \multirow[t]{3}{*}{ UST } & NA & NA & $1 / 1$ & $C R^{*}$ & NA & 31 & [8] \\
\hline & & $\begin{array}{l}\text { Pat 1: } 1.5 \mathrm{mg} / \mathrm{kg} \\
\text { every } 2 \mathrm{mths} \\
\text { Pat 2: } 1 \mathrm{mg} / \mathrm{kg} \\
\text { every } 2 \mathrm{mths}\end{array}$ & NA "weeks" & $2 / 2$ & $C R C R$ & IVIG- & 155 & [3] \\
\hline & & $\begin{array}{l}0.75 \mathrm{mg} / \mathrm{kg} \\
\text { every } 3 \mathrm{mths}\end{array}$ & NA & $1 / 1$ & $C R$ & - & 12 & [6] \\
\hline \multirow[t]{4}{*}{ IL-17 } & \multirow[t]{4}{*}{ SEC } & $\begin{array}{l}150 \mathrm{mg} / \mathrm{wkly} \\
\text { ervery } 4 \text { wks }\end{array}$ & 1 & $1 / 1$ & $C R$ & MTX 5 mg/wk & 12 & [8] \\
\hline & & 75 mg/wk & NA & $1 / 1$ & $C R^{* *}$ & PRED $2.5 \mathrm{mg} / \mathrm{d}$ & 2 & [19] \\
\hline & & 150 mg mthly & 14 & $1 / 1$ & $C R^{* *}$ & - & $8^{* * * *}$ & [15] \\
\hline & & $\begin{array}{l}300 \text { mg every } 4 \text { wks, } \\
\text { initially } 5 \text { doses } 300 \\
\text { mg wkly }\end{array}$ & 2 & $1 / 1$ & $C R^{* *}$ & - & 6 & [24] \\
\hline
\end{tabular}

Abbr. ADA-adalimumab, ANA-anakinra, CANA-canakinumab, CR-complete response, ETA-etanercept, IFL-infliximab, MP-methylprednisolone, NA-not available, NRno response, PRED-prednisolone, PR-partial response, SEC-Secukinumab, UST-ustekinumab, * secondary failure after 7 months, changed to SEC **mild relaps, *** 21 months of follow-up interval after cessation of treatment, ${ }^{* * *} 4$ months of follow-up interval after cessation of treatment. 


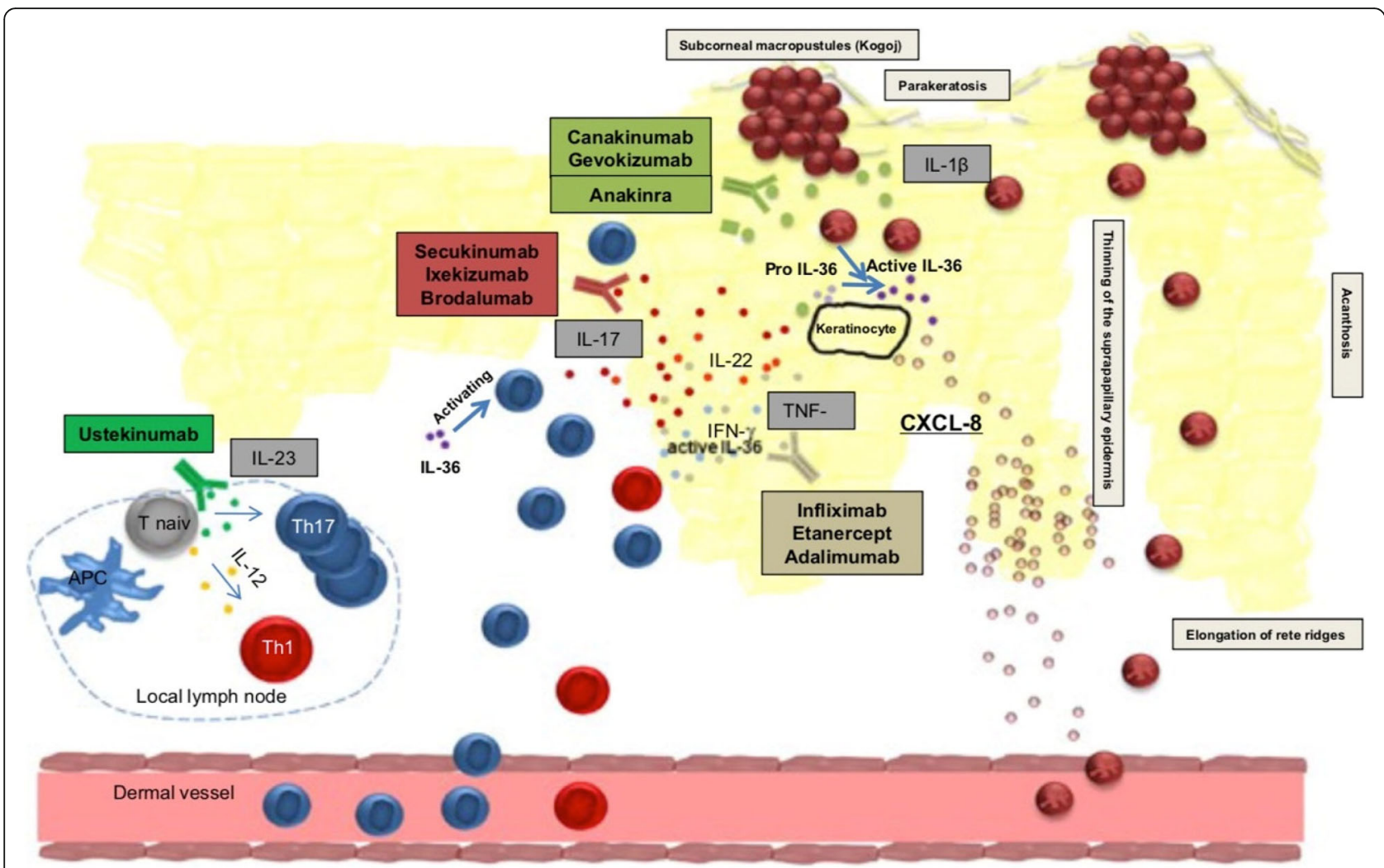

Fig. 6 Pathogenesis of GPP (main mediators) including targets for immunotherapy [2] (reprinted with permission)

complete response [2]. While there is evidence that autoinflammation has a role in the pathogenesis of psoriasis and GPP $[11,29]$ treatment responses to IL-1 blocking agents were lowest in our review (Table 3). This is especially true for the reported doses of Anakinra of maximally $6 \mathrm{mg} / \mathrm{kg}$. Interestingly, adult GPP patients with IL-1 treatments also only showed a $20 \%$ rate of complete response $[2,37]$. It was hypothesized that the inefficacy of anti-IL-1 treatment might be due to the yet not clear activity of IL-1 downstream of IL-36 [35]. Inhibition to IL-12/23 blocking agents (ustekinumab) was successful in all four patients (Tables 2,3). This biologic agent has before been shown to be effective in two pediatric DITRA patients. Nevertheless, high doses were required to achieve complete response [3]. Meanwhile a recently published case report also showed efficacy with standard dosing [6]. In adult GPP patients six out seven ustekinumab treated flares had complete response [2]. Treatment with IL17 inhibition (secukinumab) also showed a complete response in all four flares (Tables 2,3) and even as monotherapy in two of them [15, 24]. In 32 adults complete remission was achieved in $76 \%$ and partial response $27 \%$ with this substance [2]. Taken into account that with either IL-12/23 and with Il-17 inhibition mild relapses occurred, these two substances have to be considered as an effective option in pediatric DITRA. In addition patients may also benefit from our approach of weekly administered adalimumab which has -to the best of our knowledge- not been reported in pediatric DITRA before.

Table 3 Outcome of biological treatment in 28 flares of 13 pediatric patients

\begin{tabular}{llllll}
\hline Targets & Flares $n$ & \multicolumn{2}{l}{ Clinical response [flares $n(\%)]$} & Median treatment duration in months (range) \\
\cline { 2 - 4 } & & CR & PR & NR & \\
\hline TNF-a & 12 & $7(58)$ & $1(8)$ & $4(33)$ & $6.5(0.2-26)$ \\
IL-1 & 8 & $1(13)$ & $1(13)$ & $6(76)$ & $2.5(0.1-36)$ \\
IL-12/23 & 4 & $4(100)$ & - & - & $13.5(5-31)$ \\
IL-17 & 4 & $4(100)$ & - & - & $8(2-12)$ \\
Total & 28 & $16(57)$ & $2(7)$ & $10(36)$ & $5.5(0.1-36)$ \\
\hline
\end{tabular}

Abbr. CR-complete response, PR-partial response, NR-no response. 
The reason for the heterogeneous response to biologicals is unclear, although a correlation between the severity of the disease and the degree of the functional impairment of the mutated IL36RN could be shown [34]. Besides this proposed phenotype-genotype association with severe clinical manifestation in patients with nonsense mutation further factors seem to play a role as reported by several authors who showed that similar treatments in patients with identical mutations resulted in different outcome [5, $10,28,31,32]$. Our review did not show an association of treatment response with genetic mutation either, be it because of the small number of the cohort or because there is no direct one (data not shown).

Limitations of our scoping that may lead to bias could result from lacking data on long-term observation as follow-up intervals after cessation of treatment were only reported in two flares. Furthermore our defined remission period of one month is relatively short. This restriction was necessary due to four flares reporting CR with shorter observation periods than 6 months. These limitations might be important as the natural course of the disease is characterized by changing patterns of activity. Secondly the role of concomitant treatment in four flares with $C R$ (low dose MTX and PRED, ACI and IVIG) can not be clearly evaluated. It is obvious that a retrospective data collection on a small cohort of patients is prone to bias through relative predominance of singular events. On the other hand, regarding the scarcity of the published cases and the need to introduce effective treatments it seems necessary to analyze the existing data.

In summary we have reviewed the literature on pediatric DITRA patients that have been treated with biologicals. Good response was seen with TNF blocking agents and especially with inhibition of IL-17 and IL-12/23, while antiIL treatment was less effective. For accurate evaluation of the efficacy of these substances-also in respect to induction and maintenance treatment- long-term observation is necessary. Although clincal trials with biologicals in GPP are under way- including adalimumab in japanese adolescentsuse of these agents in pediatric patients with DITRA is offlabel (clinicaltrials.gov). If the recently developed antihuman and anti-mouse IL-36R antagonist monoclonal antibodies will have clinical effects for DITRA patients has to be proven [14].

\section{Conclusion}

DITRA is a rare disease that has to be considered in GPP with systemic inflammation and fever. For diagnostic purposes close collaboration between clinicians and geneticists is important. DITRA can be effectively treated with specific biological inhibition of TNF-alpha, IL-12/23 and IL- 17, while IL-1 treatment seems less effective. Further reports and studies of biological treated pediatric DITRA patients are warranted for evaluation of optimal treatment.

\section{Abbreviations}

ACl: Acitretin; ADA: Adalimumab; ANA: Anakinra; APRE: Apremilast; CAMPS: Caspase activation and recruitment domain 14-mediated psoriasis; CANA: Canakinumab; CARD: Caspase activation and recruitment domain; comp het: Compound heterzygosity; CR: Complete response; CRB: Complete response with breakthrough; CS: Corticosteroids; CSA: Ciclosporine; DAP: Dapsone; DITRA: Deficiency of interleukin-36 receptor antagonist; ETA: Etanercept; FHL5: Hemophagocytic lymphohistiocytosis type 5; GPP: Generalized pustular psoriasis; Het: Heterozygosity; Ho: Homozygosity; IFL: Infliximab; IL-1: interleukin-1; IL-12/23: Interleukin-12/23; IL36RN: Interleukin-36 receptor antagonist; IL-17: Interleukin-12; ISO: Isotretinoin; MAPKs: Mitogen activated protein kinases; MPP: Methylprednisolone; MTX: Methotrexate; NA: Not available; NFKB: Nuclear factor kappa B; NR: No response; PR: Partial response; PRED: Prednisolone; PUVA: Psoralen plus ultraviolet A; RET: Retionoids; SEC: Secukinumab; STXBP2: Syntaxin-binding protein 2; THAL: Thalidomide; TNF-a: Tumornecrosisfactor- $a_{\text {; }}$ UST: Ustekinumab.

\section{Acknowledgements}

Not applicable.

\section{Availabiltiy of data and material}

All data generated or analyzed during this study are included in this published article and can be found in "pubmed" as described in our section "methods".

\section{Authors' contribution}

$\mathrm{TH}$ analyzed and interpreted the patient data, FG wrote the case report from pediatric perspective, FB collected the data from pubmed research, DC wrote the introduction and analyzed literature data, CS wrote the section on results and analyzed data, CSM wrote case report from dermatologic perspective and PvdD revised the case report, FH performed the wholeexom screening, MR contributed with extensive literature search on different mutations, CK has substancially revised the data. All authors read an approved the final manuscript and agreed both to be personally accountable for the contribution and ensured that questions related to the accuracy or integrity of the work were appropriately investigated, resolved and documented in the literature.

\section{Funding}

This study was not funded.

\section{Ethics approval and consent to participate}

Name of the ethics committee: Landesärztekammer Baden-Württemberg, Liebknechtstr. 33, 70565 Stuttgart.

Approval and consent was obtained on February 5th, 2019.

\section{Consent for publication}

Informed consent was obtained of both parents in written and of the pediatric patient in oral form for publishing the case report and the pictures.

\section{Competing interests}

The authors declare that they have no competing interests.

\section{Author details}

'Department of Pediatric Rheumatology, Klinikum Stuttgart, Olgahospital Stuttgart, Stuttgart, Germany. ${ }^{2}$ Department of Dermatology, Klinikum Stuttgart, Bad Cannstatt, Stuttgart, Germany. ${ }^{3}$ Department of Pediatrics, Dr. von Hauner Children's Hospital, University Hospital, LMU, Munich, Germany

Received: 21 February 2019 Accepted: 12 June 2019

Published online: 08 July 2019

\section{References}

1. Bal E, Lim AC, et al. Mutation in IL36RN impairs the processing and regulatory function of the interleukin-36-receptor antagonist and is associated with DITRA syndrome. Exp Dermatol. 2017. 
2. Boehner A, Navarini AA, et al. Generalized pustular psoriasis - a model disease for specific targeted immunotherapy, systematic review. Exp Dermatol. 2018.

3. Bonekamp N, Caorsi R, et al. High-dose ustekinumab for severe childhood deficiency of interleukin-36 receptor antagonist (DITRA). Ann Rheum Dis. 2018;77(8):1241-3.

4. Bryceson YT, Pende D, et al. A prospective evaluation of degranulation assays in the rapid diagnosis of familial hemophagocytic syndromes. Blood. 2012;119(12):2754-63.

5. Carapito R, Isidor B, et al. Homozygous IL36RN mutation and NSD1 duplication in a patient with severe pustular psoriasis and symptoms unrelated to deficiency of interleukin-36 receptor antagonist. $\mathrm{Br} J$ Dermatol. 2015;172(1):302-5.

6. Cherqaoui B Jr, Rossi-Semerano L, et al. Standard dose of Ustekinumab for childhood-onset deficiency of interleukin-36 receptor antagonist. Ann Rheum Dis. 2018;77(12):e88.

7. Choon SE, Lai NM, et al. Clinical profile, morbidity, and outcome of adultonset generalized pustular psoriasis: analysis of 102 cases seen in a tertiary hospital in Johor, Malaysia. Int J Dermatol. 2014;53(6):676-84.

8. Cordoro KM, Ucmak D, et al. Response to interleukin (IL)-17 inhibition in an adolescent with severe manifestations of IL-36 receptor antagonist deficiency (DITRA). JAMA Dermatol. 2017:153(1):106-8.

9. Cowen EW, Goldbach-Mansky R. DIRA, DITRA, and new insights into pathways of skin inflammation: what's in a name? Arch Dermatol. 2012;148(3):381-4

10. Cuperus $E$, Koevoets $R$, et al. Juvenile interleukin-36 receptor antagonist deficiency (DITRA) with c.80T>C (p.Leu27Pro) mutation successfully treated with etanercept and acitretin. JAAD Case Rep. 2018;4(2):192-5.

11. D'Erme AM, Wilsmann-Theis D, et al. IL-36gamma (IL-1F9) is a biomarker for psoriasis skin lesions. J Invest Dermatol. 2015;135(4):1025-32.

12. Debets $R$, Timans JC, et al. Two novel IL-1 family members, IL-1 delta and IL-1 epsilon, function as an antagonist and agonist of NF-kappa B activation through the orphan IL-1 receptor-related protein 2. J Immunol. 2001;167(3):1440-6.

13. Federici S, Gattorno M. A practical approach to the diagnosis of autoinflammatory diseases in childhood. Best Pract Res Clin Rheumatol. 2014;28(2):263-76.

14. Ganesan R, Raymond EL, et al. Generation and functional characterization of anti-human and anti-mouse IL-36R antagonist monoclonal antibodies. MAbs. 2017;9(7):1143-54.

15. Ho PH, Tsai TF. Successful treatment of refractory juvenile generalized pustular psoriasis with secukinumab monotherapy: a case report and review of published work. J Dermatol. 2018.

16. Hussain S, Berki DM, et al. IL36RN mutations define a severe autoinflammatory phenotype of generalized pustular psoriasis. J Allergy Clin Immunol. 2015;135(4):1067-1070 e1069.

17. Jin $\mathrm{H}, \mathrm{ChoH}$, et al. Clinical features and course of generalized pustular psoriasis in Korea. J Dermatol. 2015;42(7):674-8.

18. Korber A, Mossner $\mathrm{R}$, et al. Mutations in IL36RN in patients with generalized pustular psoriasis. J Invest Dermatol. 2013;133(11):2634-7.

19. Kostner K, Prelog M, et al. Successful use of secukinumab in a 4-year-old patient with deficiency of interleukin-36 antagonist. Rheumatology (Oxford). 2018;57(5):936-8.

20. Lau BW, Lim DZ, et al. Juvenile generalized pustular psoriasis is a chronic recalcitrant disease: an analysis of 27 patients seen in a tertiary hospital in Johor, Malaysia. Int J Dermatol. 2017:56(4):392-9.

21. Li X, Chen M, et al. Mutation analysis of the IL36RN gene in Chinese patients with generalized pustular psoriasis with/without psoriasis vulgaris. Dermatol Sci. 2014;76(2):132-8.

22. Marrakchi S, Guigue $P$, et al. Interleukin-36-receptor antagonist deficiency and generalized pustular psoriasis. N Engl J Med. 2011;365(7):620-8.

23. Marzano AV, Damiani $\mathrm{G}$, et al. A dermatologic perspective on autoinflammatory diseases. Clin Exp Rheumatol. 2018;110(1):32-8.

24. Molho-Pessach $\mathrm{V}$, Alyan $\mathrm{R}$, et al. Secukinumab for the treatment of deficiency of interleukin 36 receptor antagonist in an adolescent. JAMA Dermatol. 2017;153(5):473-5.

25. Murthy AS, Leslie K. Autoinflammatory skin disease: a review of concepts and applications to general dermatology. Dermatology. 2016;232(5):534-40.

26. Onoufriadis A, Simpson MA, et al. Mutations in IL36RN/IL1F5 are associated with the severe episodic inflammatory skin disease known as generalized pustular psoriasis. Am J Hum Genet. 2011;89(3):432-7.

27. Pagel J, Beutel K, et al. Distinct mutations in STXBP2 are associated with variable clinical presentations in patients with familial hemophagocytic lymphohistiocytosis type 5 (FHL5). Blood. 2012;119(25):6016-24.
28. Pan J, Qiu L, et al. Juvenile generalized pustular psoriasis with IL36RN mutation treated with short-term infliximab. Dermatol Ther. 2016;29(3):164-7.

29. Rivas Bejarano JJ, Valdecantos WC. Psoriasis as autoinflammatory disease. Dermatol Clin. 2013:31(3):445-60

30. Robinson A, Van Voorhees AS, et al. Treatment of pustular psoriasis: from the medical Board of the National Psoriasis Foundation. J Am Acad Dermatol. 2012:67(2):279-88.

31. Rossi-Semerano L, Piram M, et al. First clinical description of an infant with interleukin-36-receptor antagonist deficiency successfully treated with anakinra. Pediatrics. 2013;132(4):e1043-7.

32. Song HS, Yun SJ, et al. Gene mutation analysis in a korean patient with early-onset and recalcitrant generalized pustular psoriasis. Ann Dermatol. 2014;26(3):424-5.

33. Sugiura K, Takemoto A, et al. The majority of generalized pustular psoriasis without psoriasis vulgaris is caused by deficiency of interleukin-36 receptor antagonist. J Invest Dermatol. 2013;133(11):2514-21.

34. Tauber M, Bal E, et al. IL36RN mutations affect protein expression and function: a basis for genotype-phenotype correlation in pustular diseases. J Invest Dermatol. 2016;136(9):1811-9.

35. Tauber $M$, Viguier $M$, et al. Partial clinical response to anakinra in severe palmoplantar pustular psoriasis. Br J Dermatol. 2014;171(3):646-9.

36. Towne JE, Garka KE, et al. Interleukin (IL)-1F6, IL-1F8, and IL-1F9 signal through IL-1Rrp2 and IL-1RACP to activate the pathway leading to NFkappaB and MAPKs. J Biol Chem. 2004;279(14):13677-88.

37. Viguier $M$, Guigue $P$, et al. Successful treatment of generalized pustular psoriasis with the interleukin-1-receptor antagonist Anakinra: lack of correlation with IL1RN mutations. Ann Intern Med. 2010;153(1):66-7.

38. Wang TS, Chiu HY, et al. Correlation of IL36RN mutation with different clinical features of pustular psoriasis in Chinese patients. Arch Dermatol Res. 2016; 308(1):55-63.

39. Wang $Y$, Cheng R, et al. Clinical profiles of pediatric patients with GPP alone and with different IL36RN genotypes. J Dermatol Sci. 2017:85(3):235-40.

40. Zhu $\mathrm{T}$, Jin $\mathrm{H}$, et al. Association of IL36RN mutations with clinical features, therapeutic response to acitretin, and frequency of recurrence in patients with generalized pustular psoriasis. Eur J Dermatol. 2018;28(2):217-24.

\section{Publisher's Note}

Springer Nature remains neutral with regard to jurisdictional claims in published maps and institutional affiliations.

Ready to submit your research? Choose BMC and benefit from:

- fast, convenient online submission

- thorough peer review by experienced researchers in your field

- rapid publication on acceptance

- support for research data, including large and complex data types

- gold Open Access which fosters wider collaboration and increased citations

- maximum visibility for your research: over $100 \mathrm{M}$ website views per year

At BMC, research is always in progress.

Learn more biomedcentral.com/submissions 